\title{
Mineralization of Azo Dye Using Combined Photo-Fenton and Photocatalytic Processes under Visible Light
}

\author{
Selma K. Kuriechen, ${ }^{1}$ Sepperumal Murugesan, ${ }^{2}$ and Samuel Paul Raj ${ }^{1}$ \\ ${ }^{1}$ School of Energy, Environment, and Natural Resources, Madurai Kamaraj University, Madurai, Tamil Nadu 625 021, India \\ ${ }^{2}$ Department of Inorganic Chemistry, School of Chemistry, Madurai Kamaraj University, Madurai, Tamil Nadu 625 021, India \\ Correspondence should be addressed to Sepperumal Murugesan; smsan03@yahoo.co.uk
}

Received 31 December 2012; Accepted 18 March 2013

Academic Editor: Hicham Idriss

Copyright (c) 2013 Selma K. Kuriechen et al. This is an open access article distributed under the Creative Commons Attribution License, which permits unrestricted use, distribution, and reproduction in any medium, provided the original work is properly cited.

\begin{abstract}
Visible-light-assisted photodegradation of an azo dye, Reactive Red 180 (RR180), in the presence of nitrogen-doped $\mathrm{TiO}_{2}\left(\mathrm{~N}-\mathrm{TiO}_{2}\right)$ has been studied. The photodegradation of RR180 is evaluated through decolorization studies and total organic carbon analysis. The efficacy of hydrogen peroxide $\left(\mathrm{H}_{2} \mathrm{O}_{2}\right)$, potassium peroxomonosulfate (oxone or PMS), and potassium peroxodisulfate (PDS) in improving the photodegradation of the dye in the $\mathrm{N}-\mathrm{TiO}_{2}-\mathrm{RR} 180$ system is also examined. The effect of combining photo-Fentonlike reaction with $\mathrm{N}-\mathrm{TiO}_{2}$-mediated photodegradation of RR180 under visible light has been investigated. The photoactivity of $\mathrm{N}-\mathrm{TiO}_{2}-\mathrm{RR} 180-\mathrm{Fe}^{3+} / \mathrm{Cu}^{2+}$-oxidant systems is compared with the individual techniques of photocatalysis and photo-Fenton-like reactions. The coupled system possesses superior photomineralization ability towards the abatement of RR180.
\end{abstract}

\section{Introduction}

Now a days, combining several oxidation systems for the degradation and mineralization of organic pollutants has become a common practice, for the reason that a single process usually cannot reach a desirable effectiveness in the degradation and mineralization of organic pollutants. Heterogeneous photocatalysis using titania photocatalyst has been established as a principal advanced oxidation process (AOP) for wastewater treatment. For a century, photo-Fenton reactions were also considered widely for the removal of organic pollutants [1-7]. The combination of heterogeneous photocatalysis with another AOP can be cost-effective as long as this combination produces a synergic effect. In the earlier efforts to increase the photodegradation efficiency through combined systems, photocatalysis coupled with ultrasonic treatment [8], integrating photocatalysis with membrane filtration [9], or combinations of photo-electro-Fenton [10], sono-Fenton [11], and electro-Fenton [12] processes were carried out, and better performances were observed. Not many attempts were made in pairing photocatalysis and photo-Fenton-like reactions for wastewater treatment. In general, the rate of photodegradation of pollutants is proportional to the efficiency of reactive radical formation. In photocatalysis- and photo-Fenton-coupled systems, two independent sources of hydroxyl radicals exist: (a) occurrence of hydroxyl radicals in photocatalytic reactions on titanium dioxide and (b) Fe(III) aqua complexes are independent and are more efficient sources of hydroxyl radicals through the photoredox reaction [13]. But the efficiency of photocatalytic process is limited by the recombination of photogenerated electrons and holes in the semiconductor phase. However, it can be suppressed by the addition of suitable scavengers of particular charge carriers.

In the present investigation, effect of adding metal ions $\left(\mathrm{Fe}^{3+}\right.$ or $\left.\mathrm{Cu}^{2+}\right)$ into the $\mathrm{TiO}_{2}$-mediated photodegradation of Reactive Red 180, an azo dye, under visible light is studied. The potential of coupled systems composed of nitrogendoped titania or pure $\mathrm{TiO}_{2}$ (Degussa P25), metal ions $\left(\mathrm{Fe}^{3+}\right.$ or $\mathrm{Cu}^{2+}$ ) and oxidants, namely, potassium peroxomonosulfate (PMS), potassium peroxodisulfate (PDS), and hydrogen peroxide $\left(\mathrm{H}_{2} \mathrm{O}_{2}\right)$ towards the mineralization of RR180 under visible light is examined. 


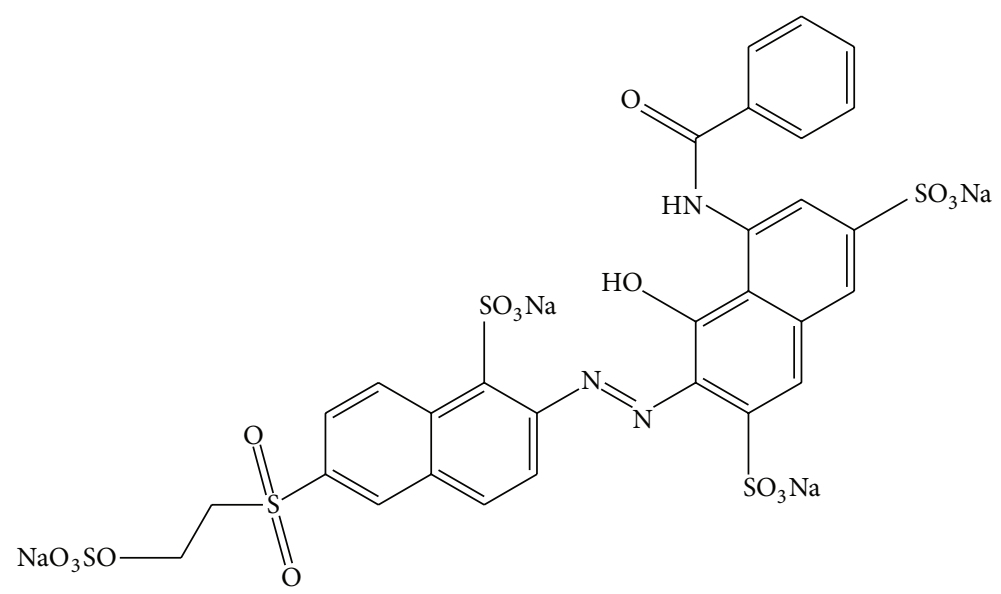

FIGURE 1: Structure of RR180.

\section{Experimental Details}

2.1. Preparation and Characterization of Nitrogen-Doped Titania Catalyst. The nitrogen-doped $\mathrm{TiO}_{2}\left(\mathrm{~N}-\mathrm{TiO}_{2}\right)$ was synthesized through hydrolysis of $\mathrm{TiCl}_{4}$ followed by the addition of a solution of hydrazine hydrate [14]. Briefly, $\mathrm{TiCl}_{4}(0.05 \mathrm{~mol})$ was added dropwise into $400 \mathrm{~mL}$ double distilled water while it was surrounded by an ice bath. After repeated stirring, $5 \mathrm{M}$ solution of hydrazine hydrate was added dropwise so as to adjust the $\mathrm{pH}$ of the solution to 5.5. It was then kept overnight for aging. The resulting precipitate was centrifuged and filtered, washed with double distilled water for several times (to remove the chloride content), dried at $343 \mathrm{~K}$, and then calcined at $673 \mathrm{~K}$ for $3 \mathrm{~h}$ to get the pale yellow-colored nitrogen-doped $\mathrm{TiO}_{2}$ powder.

The crystal structure and phase purity of the prepared samples were analyzed by recording powder X-ray diffraction (XRD) patterns on a XPERT-PRO diffractometer with $\mathrm{Cu} \mathrm{K} \alpha$ radiation $(\lambda=1.5405 \AA)$ in the $2 \theta$ range of $10-80^{\circ}$ at a scan rate of $0.02^{\circ} \mathrm{s}^{-1}$. A Shimadzu $2550 \mathrm{UV}$-visible spectrophotometer equipped with a diffuse reflectance accessory (ISR 2200) was used to obtain the diffuse reflectance spectra of the catalyst over a range of 300-600 $\mathrm{nm}$.

2.2. Photocatalytic Degradation Studies. The photodegradation experiments were carried out in a photocatalytic chamber illuminated with three tungsten-halogen lamps $(250 \mathrm{~W}$, Philips, India; $\lambda=360-2000 \mathrm{~nm})$. The UV radiation $(\lambda<$ $395 \mathrm{~nm})$ was filtered using a $2 \mathrm{Mil}(50 \mu \mathrm{m}$ thick) CU clear sun control film (Garware, India). A known amount of the photocatalyst, namely, $\mathrm{TiO}_{2}$ (Degussa P25) or nitrogendoped $\mathrm{TiO}_{2}\left(\mathrm{~N}-\mathrm{TiO}_{2}\right)$, was added to a mixture containing appropriate concentrations of the dye (RR180, Figure 1) and ferric or cupric ion solutions in the photoreactor made of borosilicate glass and stirred continuously in dark for $45 \mathrm{~min}$. Finally, oxidants (PMS, PDS, or $\mathrm{H}_{2} \mathrm{O}_{2}$ ) were introduced into the above suspension, just before irradiation. The dye concentration (measured from the absorbance of the dye at its $\left.\lambda_{\text {max }}=542 \mathrm{~nm} ; \varepsilon_{\max }=19,466 \mathrm{M}^{-1} \mathrm{~cm}^{-1}\right)$ in the bulk solution at this condition (just before starting light irradiation) is used

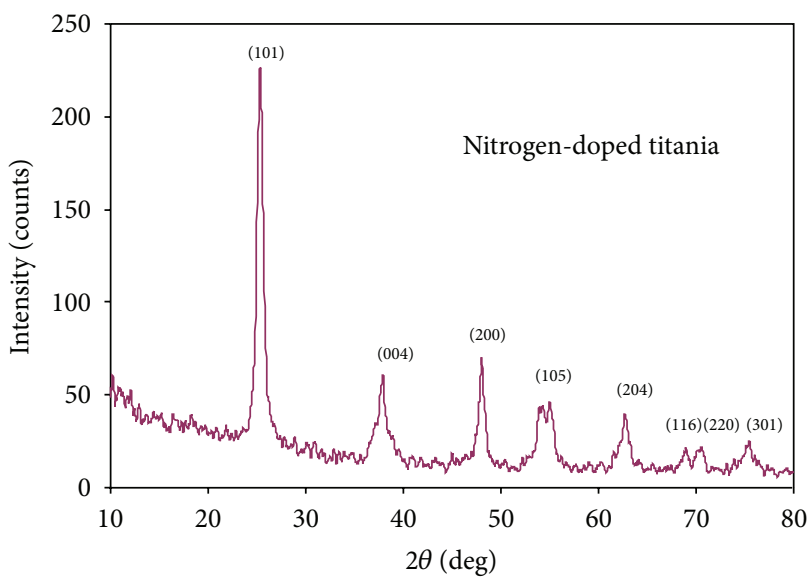

FIgURE 2: XRD pattern of $\mathrm{N}-\mathrm{TiO}_{2}$ calcined at $400^{\circ} \mathrm{C}$ for $3 \mathrm{~h}$.

as the initial concentration $\left(C_{0}\right)$. During the irradiation, $5 \mathrm{~mL}$ aliquots were withdrawn at appropriate time intervals, and the photocatalyst was removed immediately by centrifugation followed by filtration through syringe filter $(0.22 \mu \mathrm{m}$, Pall Corporation, India), and then the concentration of the dye was determined spectrophotometrically using a UVvis spectrophotometer (Shimadzu 2550). The concentration obtained at a certain irradiation time $(t)$ is denoted as $C_{t}$. The total organic carbon (TOC) content of the reaction mixture was measured using a TOC analyzer (Shimadzu TOC-V $\mathrm{CPH}_{\mathrm{H}}$ model).

\section{Results and Discussion}

3.1. Crystal Structure of $\mathrm{N}-\mathrm{TiO}_{2}$. Figure 2 illustrates the $\mathrm{X}$ ray diffractogram of nitrogen-doped $\mathrm{TiO}_{2}$ calcined at $400^{\circ} \mathrm{C}$ for $3 \mathrm{~h}$. All the observed peaks can be indexed to those corresponding to (101), (004), (200), (105), (213), (116), (220), and (301) planes of anatase phase of $\mathrm{TiO}_{2}$ (JCPDS file no. 211272), confirming the formation of particles with pure anatase phase. The average size of the anatase crystallites estimated using the Scherrer equation, $D=0.9 \lambda / \beta \cos \theta$, $(D$-the grain 


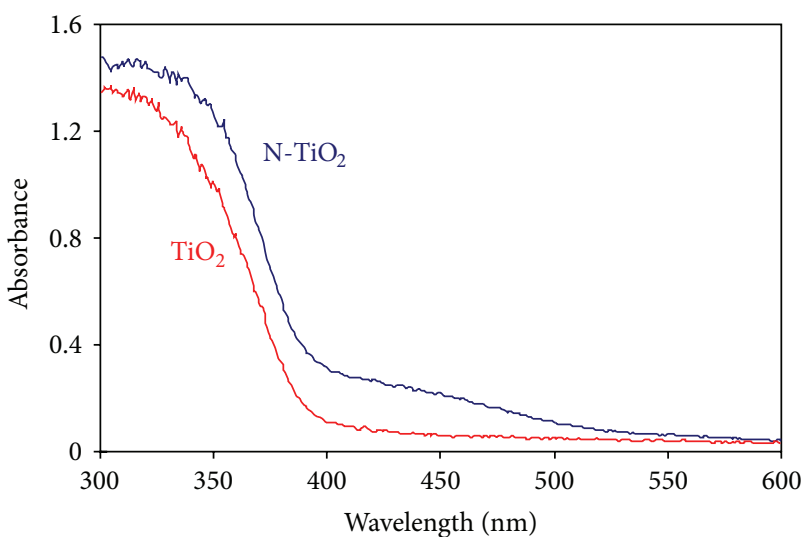

Figure 3: UV-vis absorption spectra of $\mathrm{TiO}_{2}$ (P25) and $\mathrm{N}-\mathrm{TiO}_{2}$ calcined at $400^{\circ} \mathrm{C}$ for $3 \mathrm{~h}$.

diameter; $\lambda$-wavelength of $X$-ray used; $\beta$-full width at half maximum of the peak in radians; $\theta$-the angle of diffraction in degree) is about $10 \mathrm{~nm}$. It is to be noted that the doped samples exhibit the typical structure of anatase $\mathrm{TiO}_{2}$ crystal without any detectable dopant-related peaks. This may be due to the low concentration of the doped species, since limited amount of dopant may have moved either into the interstitial positions or into the substitutional sites of the $\mathrm{TiO}_{2}$ crystal structure $[14,15]$.

3.2. Optical Properties. Figure 3 shows the diffuse reflectance spectrum of nitrogen-doped $\mathrm{TiO}_{2}$ particles together with that of Degussa P25 $\mathrm{TiO}_{2}$. Degussa P25 shows the fundamental absorbance stopping edge at $385 \mathrm{~nm}$. A noticeable shift in the absorption edge towards the visible-light region $(\lambda>$ $400 \mathrm{~nm}$ ) observed for the nitrogen-doped $\mathrm{TiO}_{2}$ catalyst may be due to the incorporation of nitrogen atoms into the lattice of $\mathrm{TiO}_{2}$. The photoresponse of $\mathrm{N}-\mathrm{TiO}_{2}$ in the visible light can be ascribed to the presence of oxygen vacancy states, due to the formation of $\mathrm{Ti}^{3+}$ species, between the valence and the conduction bands in the $\mathrm{TiO}_{2}$ band structure [16]. The vacant oxygen sites may have been substituted by nitrogen atoms and these nitrogen sites are responsible for the visiblelight sensitivity. The pale yellow color of nitrogen-doped $\mathrm{TiO}_{2}$ also implied that the $\mathrm{N}-\mathrm{TiO}_{2}$ absorbs some lower wavelength portion of the visible spectrum with low absorption intensity.

3.3. Photodegradation of RR180. There was no conspicuous decolorization of RR180 when the experiments were carried out with (i) RR180 + light, (ii) RR180 + PDS + light, (iii) $\mathrm{RR} 180+$ PMS + light, and (iv) RR180 $+\mathrm{H}_{2} \mathrm{O}_{2}+$ light which indicated that neither photolysis nor simple oxidation by the strong oxidants occurred (Figure 4). But when similar experiments were performed in the presence of $\mathrm{N}^{-\mathrm{TiO}_{2}}$ (each of the above combinations with $\mathrm{N}-\mathrm{TiO}_{2}$ ), a drastic increase in the degradation of RR180 (appreciable decrease in the concentration of dye with time) was observed (Figure 4). This reveals that the RR180 degradation takes place through photocatalytic process.

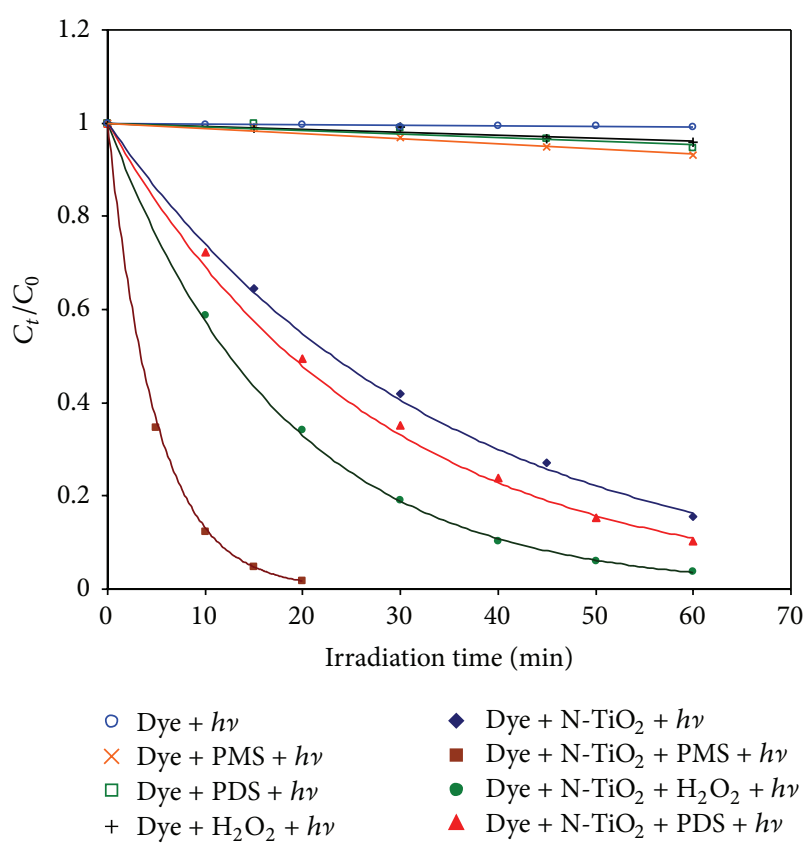

FIGURE 4: Experimental data for the photodegradation of RR180 in the presence of oxidants. $\mathrm{C}_{\mathrm{N}-\mathrm{TiO}_{2}}=1.428 \mathrm{~g} \mathrm{~L}^{-1} ; \mathrm{C}_{\mathrm{RR} 180}=5 \times 10^{-5} \mathrm{M}$; $\mathrm{C}_{\mathrm{PMS}}=\mathrm{C}_{\mathrm{PDS}}=\mathrm{C}_{\mathrm{H}_{2} \mathrm{O}_{2}}=1 \mathrm{mM}$. $\mathrm{C}_{\mathrm{PMS}}, \mathrm{C}_{\mathrm{PDS}}$, and $\mathrm{C}_{\mathrm{H}_{2} \mathrm{O}_{2}}$ represent the amount of oxidants used.

A set of experiments were carried out at natural $\mathrm{pH}$ of the solutions which were observed as 3.2 for $\mathrm{TiO}_{2}-\mathrm{Fe}^{3+}$ and 5.5 for $\mathrm{TiO}_{2}-\mathrm{Cu}^{2+}$ suspensions. It was noted that complete adsorption of dye molecules on the catalyst surface occurred in $\mathrm{TiO}_{2}-\mathrm{Fe}^{3+}$ system leading to catalyst poisoning since acidic $\mathrm{pH}$ is not favorable for $\mathrm{TiO}_{2}$. But, in $\mathrm{TiO}_{2}-\mathrm{Cu}^{2+}$ system, initial adsorption noticed was moderate. Likewise, when oxidants were introduced into the solution containing $\mathrm{TiO}_{2}-\mathrm{Fe}^{3+}$-dye, the initial adsorption noted was increased slightly and the reaction rate decreased. When oxidants were introduced in $\mathrm{TiO}_{2}-\mathrm{Cu}^{2+}$ system, better reaction rates were observed than photocatalysis as well as photo-Fenton-like processes. The $\mathrm{pH}$ of the colloidal solution where maximum reaction rate attained with $\mathrm{TiO}_{2}$ photocatalysis was 5.8. In case of $\mathrm{Fe}^{3+}$ and $\mathrm{Cu}^{2+}$-based studies (photo-Fenton-like reaction) with oxidants, highest activity was observed at $\mathrm{pH} 3.2$ and 5.5, respectively. Hence, to improve the rate of reaction as well as to minimize the adsorption, the $\mathrm{pH}$ of the $\mathrm{TiO}_{2}-\mathrm{Fe}^{3+}$-oxidant system was altered to 5.6, and interestingly, it was found that the initial adsorption was reduced to minimum with simultaneous enhancement in the rate of reaction compared to individual photocatalysis as well as photo-Fenton-like reactions. Raising the $\mathrm{pH}$ above 6 in combined systems had shown a negative impact on the photodegradation of RR180. Therefore, further studies were carried out by maintaining $\mathrm{pH}$ at 5.6.

Addition of $\mathrm{Fe}^{3+}$ or $\mathrm{Cu}^{2+}$ alone into titania resulted in detrimental effects on decolorization efficacy. It was observed that the decolorization of RR180 attained after $1 \mathrm{~h}$ visiblelight irradiation was less than 15 percent in Titania-metal ions-based systems which are much less than those obtained 


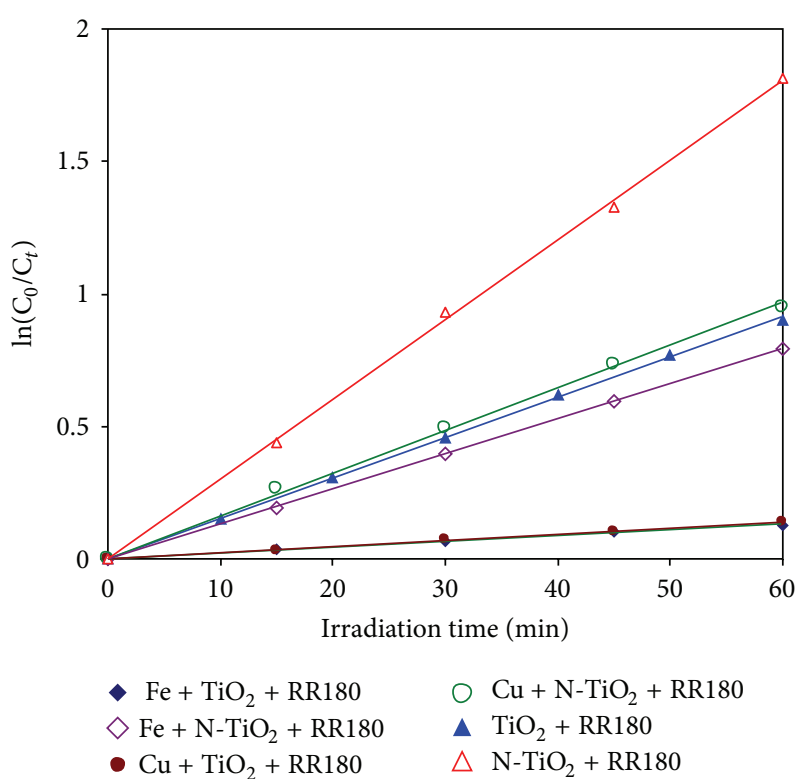

FIgURE 5: Decolorization of RR180 in the presence of $\mathrm{TiO}_{2}$ or N$\mathrm{TiO}_{2}$ and metal ions. $\left[\mathrm{TiO}_{2}\right]=\left[\mathrm{N}-\mathrm{TiO}_{2}\right]=1.428 \mathrm{~g} \mathrm{~L}^{-1} ;\left[\mathrm{Fe}^{3+}\right]=$ $\left[\mathrm{Cu}^{2+}\right]=0.2 \mathrm{mM} ;[\mathrm{RR} 180]=5 \times 10^{-5} \mathrm{M}$.

with individual systems (Figure 5). Though coupled system with $\mathrm{N}-\mathrm{TiO}_{2}$ was showing better performance than pure titania-based system, its photocatalytic activity seems to be less when compared to individual photocatalysis under similar experimental conditions. The strong negative effect on the photodegradation of dye observed upon addition of $\mathrm{Fe}^{3+}$ is due to the competitive adsorption of iron species with organic compounds on $\mathrm{TiO}_{2}$ surface. Thus, addition of $\mathrm{Fe}^{3+}$ and $\mathrm{Cu}^{2+}$ alone to $\mathrm{TiO}_{2}$ colloidal solution has shown decrement in the catalytic activity under visible light. It should be noticed that the combination of heterogeneous and homogeneous photocatalytic oxidation constitutes a very complex system in which several processes occur at the same time contributing to the overall reaction rate. The retardation of photodegradation rate on addition of $\mathrm{Fe}^{3+}$ or $\mathrm{Cu}^{2+}$ in $\mathrm{TiO}_{2}$ based systems can also be attributed to the quenching of photogenerated electrons by adsorbed metal ions which act as recombination centers that in turn reduce the generation of active radicals $[17,18]$.

An increase in the pseudo first-order rate constants (compared to individual processes) was observed when $\mathrm{TiO}_{2}-\mathrm{Fe}^{3+}$ or $\mathrm{TiO}_{2}-\mathrm{Cu}^{2+}$ photocatalysis was performed in the presence of oxidants, namely, oxone, PDS, and $\mathrm{H}_{2} \mathrm{O}_{2}$ as shown in Table 1. The increment in the rate of reaction in $\mathrm{Cu}^{2+}$ based coupled system when compared to its performance in photo-Fenton-like reactions was much noticeable than the enhancement recorded with ferric ions. The enhanced degradation observed in the coupled systems $\left(\mathrm{TiO}_{2}+\mathrm{Fe}^{3+}+\right.$ Dye + oxidant or $\mathrm{TiO}_{2}+\mathrm{Cu}^{2+}+$ Dye + oxidant) may be attributed to the enhanced generation of active radicals through decomposition of oxidants by both $\mathrm{TiO}_{2}\left(\mathrm{e}^{-}\right)$and metal ions. Therefore, both the processes are active enough
TABLE 1: Pseudo first-order rate constant values and extent of mineralization obtained in photocatalysis, photo-Fenton-like reactions, and combined systems $\left(\mathrm{TiO}_{2}\right.$ or $\mathrm{N}-\mathrm{TiO}_{2}-\mathrm{Fe}^{3+}$-oxidant and $\mathrm{TiO}_{2}$ or $\mathrm{N}-\mathrm{TiO}_{2}-\mathrm{Cu}^{2+}$-oxidant).

\begin{tabular}{|c|c|c|}
\hline Catalyst & $\begin{array}{l}\text { Photodegradation } \\
\text { rate constant } \\
k_{1} \times 10^{4}\left(\mathrm{~s}^{-1}\right)\end{array}$ & $\begin{array}{c}\text { Extent of } \\
\text { mineralization after } \\
4 \mathrm{~h}(\%)\end{array}$ \\
\hline $\mathrm{TiO}_{2}$ & 2.54 & 36 \\
\hline $\mathrm{N}-\mathrm{TiO}_{2}$ & 5.85 & 51 \\
\hline $\mathrm{TiO}_{2}+\mathrm{PMS}$ & 23.7 & 75 \\
\hline $\mathrm{N}-\mathrm{TiO}_{2}+\mathrm{PMS}$ & 27.1 & 78 \\
\hline $\mathrm{Fe}^{3+}+\mathrm{PMS}$ & 22.85 & 74 \\
\hline $\mathrm{Cu}^{2+}+\mathrm{PMS}$ & 16.95 & 70 \\
\hline $\mathrm{TiO}_{2}+\mathrm{Fe}^{3+}+\mathrm{PMS}$ & 30.13 & 91 \\
\hline $\mathrm{TiO}_{2}+\mathrm{Cu}^{2+}+\mathrm{PMS}$ & 26.52 & 89 \\
\hline $\mathrm{N}-\mathrm{TiO}_{2}+\mathrm{Fe}^{3+}+\mathrm{PMS}$ & 34.35 & 95 \\
\hline $\mathrm{N}-\mathrm{TiO}_{2}+\mathrm{Cu}^{2+}+\mathrm{PMS}$ & 28.82 & 90 \\
\hline $\mathrm{TiO}_{2}+\mathrm{PDS}$ & 4.10 & 65 \\
\hline $\mathrm{N}-\mathrm{TiO}_{2}+\mathrm{PDS}$ & 7.05 & 68 \\
\hline $\mathrm{Fe}^{3+}+\mathrm{PDS}$ & 6.95 & 71 \\
\hline $\mathrm{Cu}^{2+}+\mathrm{PDS}$ & 6.67 & 58 \\
\hline $\mathrm{TiO}_{2}+\mathrm{Fe}^{3+}+\mathrm{PDS}$ & 14.71 & 80 \\
\hline $\mathrm{TiO}_{2}+\mathrm{Cu}^{2+}+\mathrm{PDS}$ & 22.10 & 86 \\
\hline $\mathrm{N}-\mathrm{TiO}_{2}+\mathrm{Fe}^{3+}+\mathrm{PDS}$ & 19.38 & 84 \\
\hline $\mathrm{N}-\mathrm{TiO}_{2}+\mathrm{Cu}^{2+}+\mathrm{PDS}$ & 26.45 & 87 \\
\hline $\mathrm{TiO}_{2}+\mathrm{H}_{2} \mathrm{O}_{2}$ & 5.70 & 63 \\
\hline $\mathrm{N}-\mathrm{TiO}_{2}+\mathrm{H}_{2} \mathrm{O}_{2}$ & 9.25 & 67 \\
\hline $\mathrm{Fe}^{3+}+\mathrm{H}_{2} \mathrm{O}_{2}$ & 11.1 & 72 \\
\hline $\mathrm{Cu}^{2+}+\mathrm{H}_{2} \mathrm{O}_{2}$ & 6.18 & 62 \\
\hline $\mathrm{TiO}_{2}+\mathrm{Fe}^{3+}+\mathrm{H}_{2} \mathrm{O}_{2}$ & 21.45 & 77 \\
\hline $\mathrm{TiO}_{2}+\mathrm{Cu}^{2+}+\mathrm{H}_{2} \mathrm{O}_{2}$ & 17.30 & 76 \\
\hline $\mathrm{N}-\mathrm{TiO}_{2}+\mathrm{Fe}^{3+}+\mathrm{H}_{2} \mathrm{O}_{2}$ & 23.06 & 86 \\
\hline $\mathrm{N}-\mathrm{TiO}_{2}+\mathrm{Cu}^{2+}+\mathrm{H}_{2} \mathrm{O}_{2}$ & 20.85 & 76 \\
\hline
\end{tabular}

$\left[\mathrm{TiO}_{2}\right]=\left[\mathrm{N}-\mathrm{TiO}_{2}\right]=1.428 \mathrm{~g} \mathrm{~L}^{-1} ;\left[\mathrm{Fe}^{3+}\right]=\left[\mathrm{Cu}^{2+}\right]=0.2 \mathrm{mM} ;[\mathrm{RR} 180]=$ $5 \times 10^{-5} \mathrm{M}$; [Oxidants] $=2 \mathrm{mM}$.

to favor the degradation of azo dyes by promoting the generation of reactive radicals.

3.3.1. Effect of Oxidant Concentration. When the experiments were carried out at various oxidant concentrations (with constant dye, $\mathrm{TiO}_{2}$ or $\mathrm{N}-\mathrm{TiO}_{2}$ catalyst, and $\mathrm{Fe}^{3+}$ or $\mathrm{Cu}^{2+}$ concentration), an initial raise in the first-order rate constants was noted till an optimum oxidant concentration and beyond this a slight decrement in rate constants were noted (Figures 6 and 7). Among the three oxidants chosen, PMS was showing better activity in all the coupled systems based on titania and $\mathrm{N}^{-\mathrm{TiO}_{2}}$ (Table 1). PDS performed well with cupric ionbased systems in the presence of titania and $\mathrm{N}-\mathrm{TiO}_{2}$. In the coupled systems with $\mathrm{H}_{2} \mathrm{O}_{2}$, the enhancement in the reaction rate when compared to its activity in individual systems was rather low. 


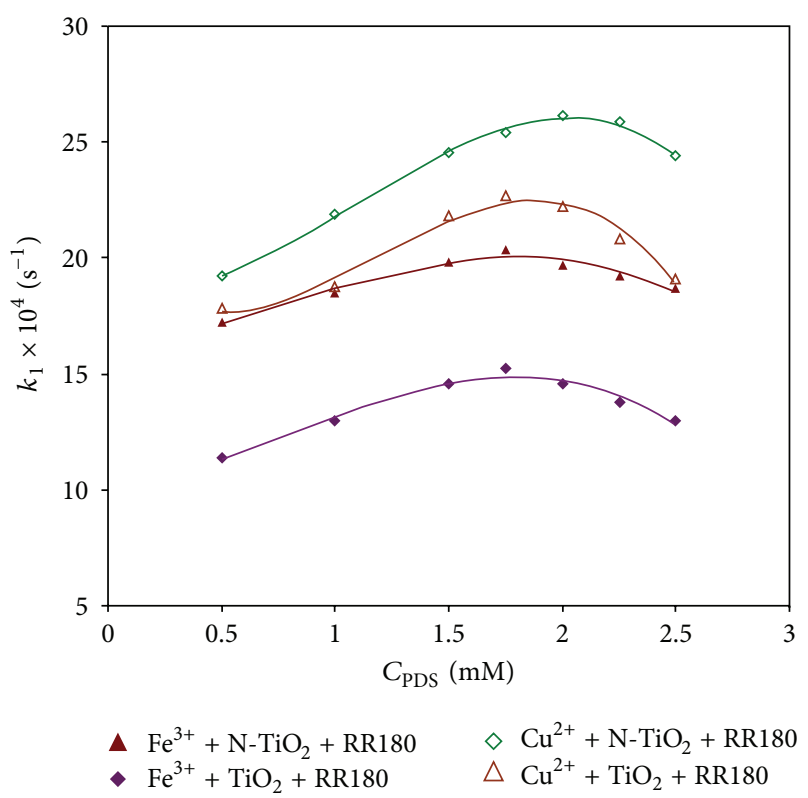

FIGURE 6: Effect of PDS concentration on the pseudo first-order rate constants for the photodegradation of RR180 in the coupled systems. $\left[\mathrm{TiO}_{2}\right]=\left[\mathrm{N}-\mathrm{TiO}_{2}\right]=1.428 \mathrm{~g} \mathrm{~L}^{-1} ;\left[\mathrm{Fe}^{3+}\right]=\left[\mathrm{Cu}^{2+}\right]=0.2 \mathrm{mM} ;[\mathrm{RR} 180]$ $=5 \times 10^{-5} \mathrm{M}$.

The positive effect of coupling photo-Fenton-like reactions with semiconductor photocatalysis can be attributed to the increased production of active radicals through decomposition of oxidants by both heterogeneous and homogeneous catalysts. Introducing potassium peroxomonosulfate into the solution leads to the formation of $\mathrm{SO}_{4}{ }^{-}$and $\mathrm{SO}_{5}{ }^{--}$radicals as well as hydroxyl radicals through radical chain reactions. Peroxomonosulfate often oxidizes faster than hydrogen peroxide and is slightly more powerful as an oxidant. PDS, a powerful oxidizing agent with a standard potential of $E_{0}=2.01 \mathrm{~V}$, can be decomposed to $\mathrm{SO}_{4}{ }^{2-}$ ion and $\mathrm{SO}_{4}{ }^{--}$by the photogenerated $\mathrm{e}^{-}$present in $\mathrm{TiO}_{2}$ as well as by the metal ions. The generated sulfate radical anion, $\mathrm{SO}_{4}{ }^{-{ }^{-}}$ $\left(E_{0}=2.6 \mathrm{~V}\right)$, has the ability to attack organic compounds by abstraction of a hydrogen atom or addition on unsaturated molecules. The initial increase in the reaction efficiency that accompanies with the addition of $\mathrm{H}_{2} \mathrm{O}_{2}$ can be attributed to the increased formation of ${ }^{\circ} \mathrm{OH}$ radicals [19]. Higher oxidant concentration reduces the apparent rate constant due to the scavenging effect of hydroxyl radicals themselves as well as by the $\mathrm{Fe}^{2+}$ ions in the solution [20]. The reduction in the rate constants noted in the presence of oxone after optimum concentration may be due to the destruction of sulfate and hydroxyl radicals by the excess $\mathrm{HSO}_{5}{ }^{-}$ions $[21,22]$. The excess radicals generated may undergo recombination or may get involved in the side reactions. At high persulfate concentration, the degradation rate decreases due to the adsorption of the excess sulfate ions (formed during the reaction) on the catalyst surface which reduces the activity of the catalyst [23].

In the paired system with oxidants $\left(\mathrm{N}^{-\mathrm{TiO}_{2}}\right.$-oxidant dye $+\mathrm{Fe}^{3+} / \mathrm{Cu}^{2+}$ oxidant dye coupled system), complete

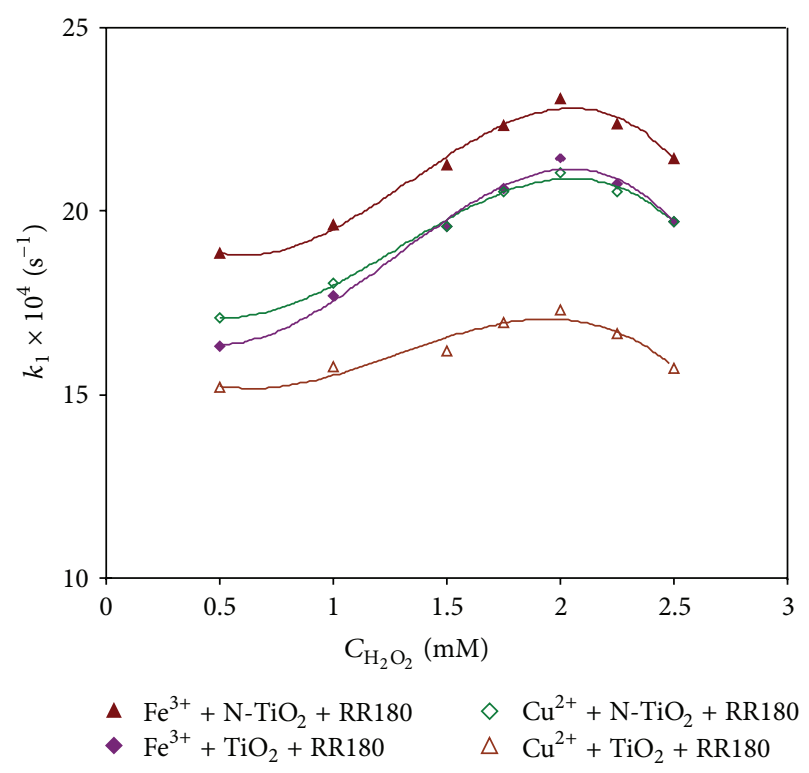

FIGURE 7: Effect of $\mathrm{H}_{2} \mathrm{O}_{2}$ concentration on the pseudo first-order rate constants for the photodegradation of RR180 in the coupled systems. $\left[\mathrm{TiO}_{2}\right]=\left[\mathrm{N}-\mathrm{TiO}_{2}\right]=1.4280 \mathrm{~g} \mathrm{~L}^{-1} ;\left[\mathrm{Fe}^{3+}\right]=\left[\mathrm{Cu}^{2+}\right]=$ $0.2 \mathrm{mM}$; $[\mathrm{RR} 180]=5 \times 10^{-5} \mathrm{M}$.

decolorization of RR180 was achieved within 30 min visiblelight illumination whereas in the individual systems (photocatalysis experiments and photo-Fenton-like reactions carried out in the presence of oxidants) longer duration was required for attaining complete decolorization. It was also noted that cupric ions, which were having less photocatalytic activity in photo-Fenton-like reactions, show better activity in coupled system along with doped as well as undoped catalyst and oxidants for the chosen compound.

3.3.2. TOC Analysis. The conversion of parent molecule into mineralized products $\left(\mathrm{CO}_{2}+\mathrm{H}_{2} \mathrm{O}\right)$ was monitored through TOC analysis. While nearly $75 \%$ TOC reduction only was observed during the degradation of RR180 using individual photocatalysis $\left(\mathrm{N}-\mathrm{TiO}_{2}-\mathrm{PMS}-\mathrm{RR} 180\right)$ or photo-Fenton-like $\left(\mathrm{Fe}^{3+}\right.$-PMS-RR180) processes, the coupled system $\left(\mathrm{TiO}_{2}-\right.$ $\mathrm{Fe}^{3+}$-Dye-PMS) exhibits $95 \%$ mineralization within $4 \mathrm{~h}$ continuous visible-light irradiation (Table 1). As observed in the decolorization studies, the coupled systems perform better than $\mathrm{TiO}_{2}$-mediated photocatalytic reactions and photo-Fenton-like reactions in the presence of oxidants. The requirement of prolonged irradiation for proper mineralization may be due to the formation of stable intermediate products which needs more time for their breakdown. The decolorization mechanism might proceed predominantly through the destruction of the azo group, by oxidation via reaction with positive holes and by reduction from conduction band electrons, while TOC was decreased only by the complete oxidation of the organic material into carbon dioxide [8]. 


\section{Conclusions}

Combination of titania-based photocatalysis and $\mathrm{Fe}^{3+}$ - or $\mathrm{Cu}^{2+}$-oxidant (photo-Fenton-like) systems produces a synergic effect that leads to an increase in the rate of photodegradation of RR180. In the coupled system, complete decolorization of RR180 was achieved within $30 \mathrm{~min}$ visiblelight illumination. A two fold increase in the TOC reduction was achieved in the coupled systems than $\mathrm{TiO}_{2}$-based photocatalysis of RR180. Enhanced degradation of RR180 may be due to the interaction of oxidants (PMS, PDS, or $\mathrm{H}_{2} \mathrm{O}_{2}$ ) with both excited titania and metal ions to produce more radicals. The degradation is favored at a $\mathrm{pH}$ of 5.6 by $\mathrm{TiO}_{2}-$ $\mathrm{Fe}^{3+}$-oxidant and $\mathrm{TiO}_{2}-\mathrm{Cu}^{2+}$-oxidant systems.

\section{Acknowledgment}

The financial support received from the UGC-UPE scheme, Madurai Kamaraj University is gratefully acknowledged.

\section{References}

[1] C. Walling, "Fenton's reagent revisited," Accounts of Chemical Research, vol. 8, no. 4, pp. 125-131, 1975.

[2] G. Ruppert, R. Bauer, and G. Heisler, "The photo-Fenton reaction: an effective photochemical wastewater treatment process," Journal of Photochemistry and Photobiology A, vol. 73, no. 1, pp. 75-78, 1993.

[3] K. Wu, Y. Xie, J. Zhao, and H. Hidaka, "Photo-Fenton degradation of a dye under visible light irradiation," Journal of Molecular Catalysis A, vol. 144, no. 1, pp. 77-84, 1999.

[4] H. Park and W. Choi, "Visible light and Fe(III)-mediated degradation of Acid Orange 7 in the absence of $\mathrm{H}_{2} \mathrm{O}_{2}$," Journal of Photochemistry and Photobiology A, vol. 159, no. 3, pp. 241247, 2003.

[5] J. Farias, G. H. Rossetti, E. D. Albizzati, and O. M. Alfano, "Solar degradation of formic acid: temperature effects on the Photo-Fenton reaction," Industrial and Engineering Chemistry Research, vol. 46, no. 23, pp. 7580-7586, 2007.

[6] N. Masomboon, C. Ratanatamskul, and M. C. Lu, "Chemical oxidation of 2,6-dimethylaniline in the fenton process," Environmental Science and Technology, vol. 43, no. 22, pp. 86298634, 2009.

[7] A. O. Ifelebuegu and C. P. Ezenwa, "Removal of endocrine disrupting chemicals in wastewater treatment by fenton-like oxidation," Water, Air, and Soil Pollution, vol. 217, no. 1-4, pp. 213-220, 2011.

[8] J. Madhavan, F. Grieser, and M. Ashokkumar, "Degradation of orange-G by advanced oxidation processes," Ultrasonics Sonochemistry, vol. 17, no. 2, pp. 338-343, 2010.

[9] S. Mozia, A. W. Morawski, M. Toyoda, and T. Tsumura, "Integration of photocatalysis and membrane distillation for removal of mono- and poly-azo dyes from water," Desalination, vol. 250, no. 2, pp. 666-672, 2010.

[10] J. Ramírez, L. A. Godínez, M. Méndez, Y. Meas, and F. J. Rodríguez, "Heterogeneous photo-electro-Fenton process using different iron supporting materials," Journal of Applied Electrochemistry, vol. 40, no. 10, pp. 1729-1736, 2010.

[11] P. J. D. Ranjit, K. Palanivelu, and C. S. Lee, "Degradation of 2,4dichlorophenol in aqueous solution by sono-Fenton method,"
Korean Journal of Chemical Engineering, vol. 25, no. 1, pp. 112$117,2008$.

[12] A. Lahkimi, M. A. Oturan, N. Oturan, and M. Chaouch, "Removal of textile dyes from water by the electro-Fenton process," Environmental Chemistry Letters, vol. 5, no. 1, pp. 3539, 2007.

[13] H. Mestankova, G. Mailhot, J. Jirkovský, J. Krýsa, and M. Bolte, "Effect of iron speciation on the photodegradation of Monuron in combined photocatalytic systems with immobilized or suspended $\mathrm{TiO}_{2}$," Environmental Chemistry Letters, vol. 7, no. 2, pp. 127-132, 2009.

[14] H. Sun, Y. Bai, W. Jin, and N. Xu, "Visible-light-driven $\mathrm{TiO}_{2}$ catalysts doped with low-concentration nitrogen species," Solar Energy Materials and Solar Cells, vol. 92, no. 1, pp. 76-83, 2008.

[15] W. L. Kostedt, A. A. Ismail, and D. W. Mazyc, "Impact of heat treatment and composition of $\mathrm{ZnO}-\mathrm{TiO}_{2}$ nanoparticles for photocatalytic oxidation of an azo dye," Industrial and Engineering Chemistry Research, vol. 47, no. 5, pp. 1483-1487, 2008.

[16] J. Yang, H. Bai, and X. Tan, "IR and XPS investigation of visible-light photocatalysis-Nitrogen-carbon-doped $\mathrm{TiO}_{2}$ film," Applied Surface Science, vol. 253, no. 4, pp. 1988-1994, 2006.

[17] M. R. Dhananjeyan, V. Kandavelu, and R. Renganathan, "An investigation of the effects of $\mathrm{Cu}^{2+}$ and heat treatment on $\mathrm{TiO}_{2}$ photooxidation of certain pyrimidines," Journal of Molecular Catalysis A, vol. 158, no. 2, pp. 577-582, 2000.

[18] P. Bouras, E. Stathatos, and P. Lianos, "Pure versus metalion-doped nanocrystalline titania for photocatalysis," Applied Catalysis B, vol. 73, no. 1-2, pp. 51-59, 2007.

[19] G. Li, X. S. Zhao, and M. B. Ray, "Advanced oxidation of orange II using $\mathrm{TiO}_{2}$ supported on porous adsorbents: the role of $\mathrm{pH}$, $\mathrm{H}_{2} \mathrm{O}_{2}$ and $\mathrm{O}_{3}$," Separation and Purification Technology, vol. 55, no. 1, pp. 91-97, 2007.

[20] L. G. Devi, S. G. Kumar, and K. M. Reddy, "Photo fenton like process $\mathrm{Fe}^{3+} /(\mathrm{NH} 4)_{2} \mathrm{~S}_{2} \mathrm{O}_{8} / \mathrm{UV}$ for the degradation of Di azo dye congo red using low iron concentration," Central European Journal of Chemistry, vol. 7, no. 3, pp. 468-477, 2009.

[21] S. K. Kuriechen, S. Murugesan, S. P. Raj, and P. Maruthamuthu, "Visible light assisted photocatalytic mineralization of Reactive Red 180 using colloidal $\mathrm{TiO}_{2}$ and oxone," Chemical Engineering Journal, vol. 174, no. 2-3, pp. 530-538, 2011.

[22] P. Maruthamuthu and P. Neta, "Radiolytic chain decomposition of peroxomonophosphoric and peroxomonosulfuric acids," Journal of Physical Chemistry, vol. 81, no. 10, pp. 937-940, 1977.

[23] M. Muruganandham and M. Swaminathan, "Photocatalytic decolourisation and degradation of Reactive Orange 4 by $\mathrm{TiO}_{2}$ UV process," Dyes and Pigments, vol. 68, no. 2-3, pp. 133-142, 2006. 

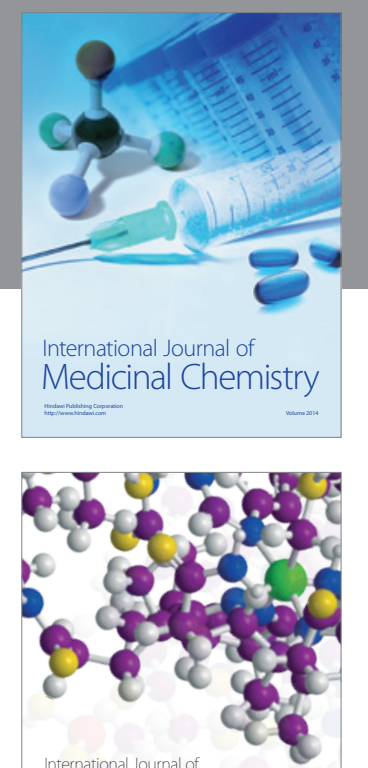

\section{Carbohydrate} Chemistry

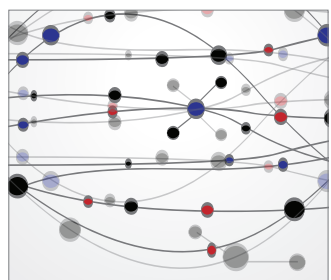

The Scientific World Journal
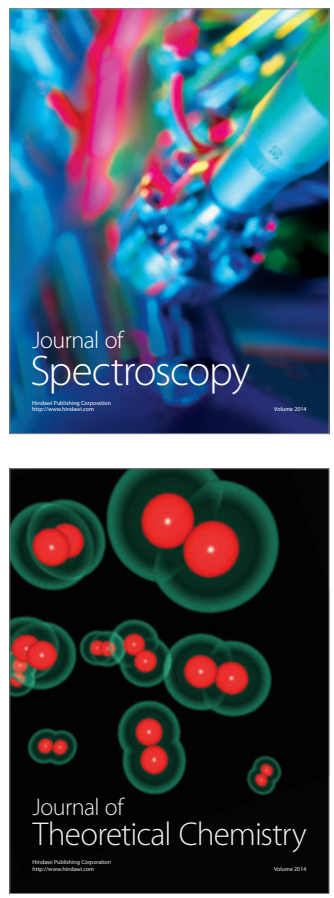
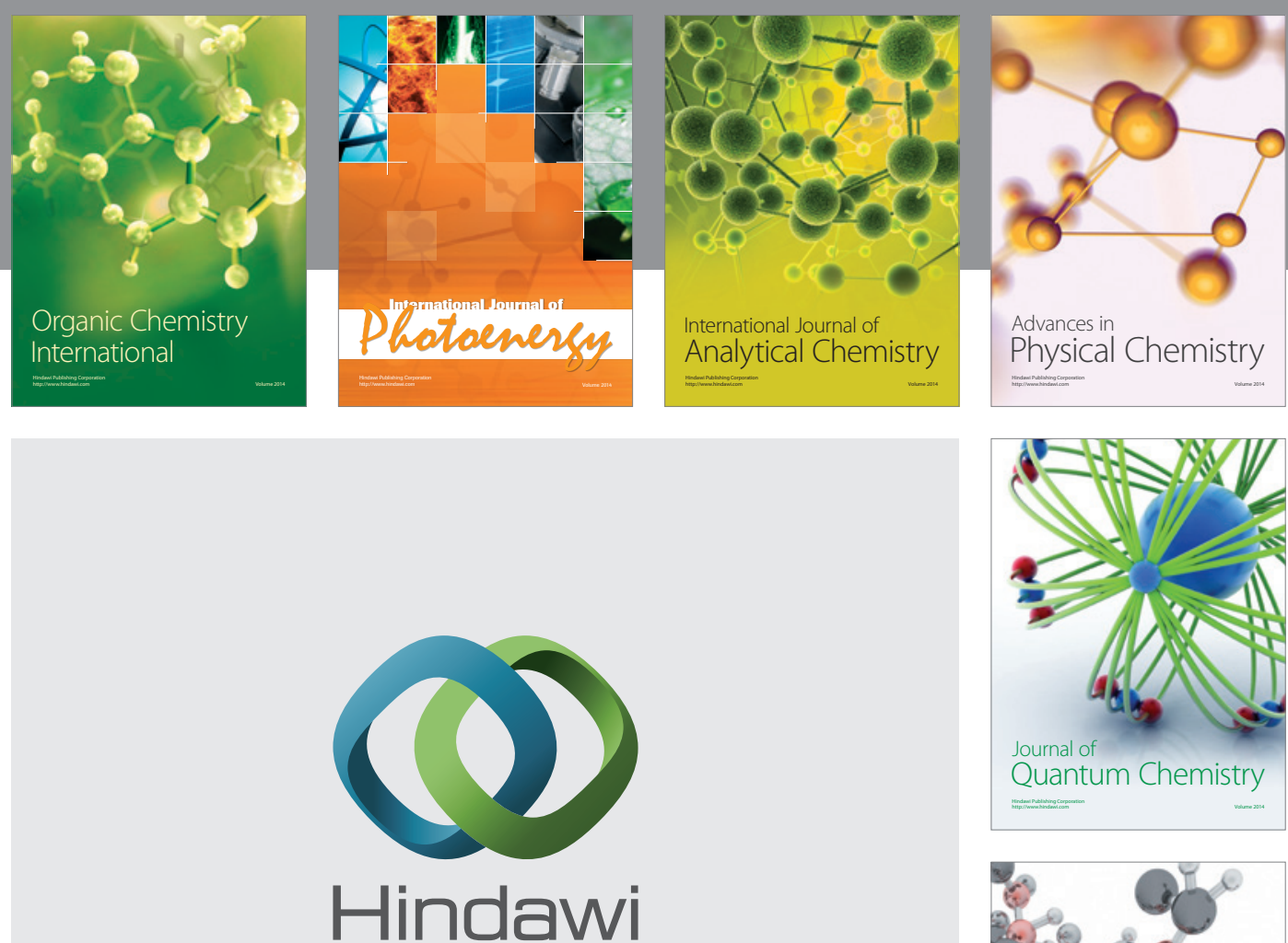

Submit your manuscripts at

http://www.hindawi.com

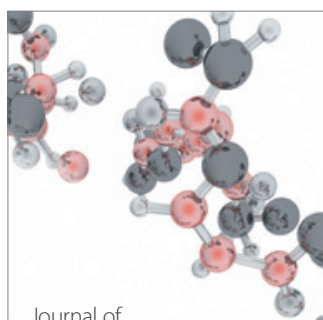

Analytical Methods

in Chemistry

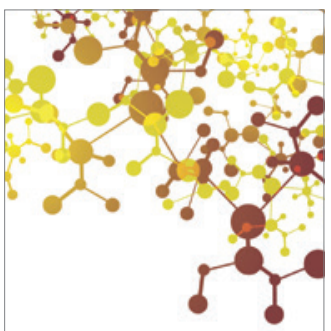

Journal of

Applied Chemistry

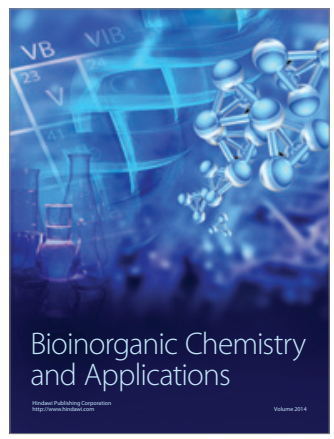

Inorganic Chemistry
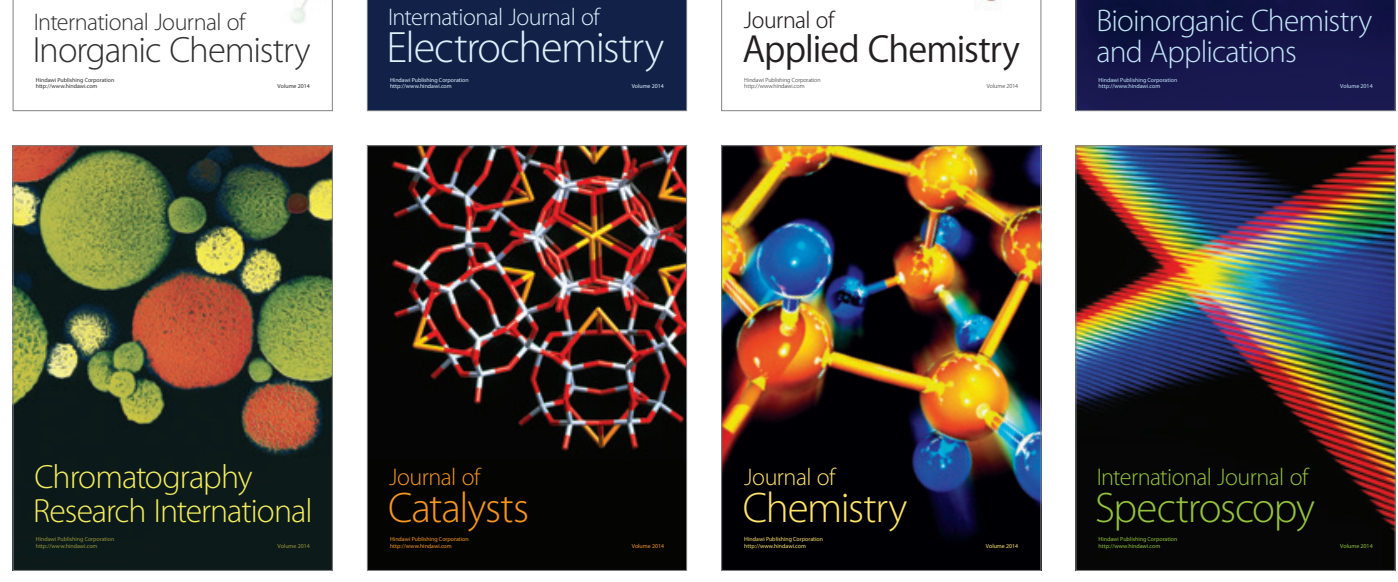